\title{
ANALISA PERANCANGAN SISTEM INFORMASI PELAPORAN FASILITAS UMUM DAN INFORMASI PEMBUATAN E-KTP UNTUK MASYARAKAT
}

\author{
${ }^{1)}$ Moh.Puji Hari Setiawan, ${ }^{2)}$ Fajar Masya \\ ${ }^{1,2)}$ Sistem Informasi, Ilmu Komputer, Universitas Mercubuana \\ ${ }^{1,2)} \mathrm{Jl}$. Raya Kranggan No.6 Jatisampurna Bekasi \\ E-Mail :'setiawanpujihari@gmail.com
}

\begin{abstract}
ABSTRAK
Fasilitas umum[1] yang disediakan oleh pemerintah merupakan alat bantu bagi masyarakat dalam menjalankan aktifitas sehari-hari. Dari mulai tempat pejalan kaki, jalan, lampu lalu lintas hingga tempat pembuangan sampah. Selain fasilitas umum[2], informasi pembuatan E-KTP juga sangat membantu masyarakat dalam mencari informasi pembuatan E-KTP agar menjadi lebih mudah. Jika terjadi kerusakan atau penyalah gunaan pada fasilitas tersebut diperlukan sebuah tindakan perbaikan atau solusi yang cepat sehingga bisa digunakan kembali. Dengan ketidak tahuan pemerintah atau aparat sekitar mengenai kerusakan atau penyalah gunaan tersebut bisa menyebabkan terganggunya aktifitas yang terjalan setiap harinya. Dengan adanya aplikasi berbasis web yang saya berinama "Report It" dapat membantu pemerintah atau aparat sekitar untuk mengetahui mengenai kerusakan atau penyalah gunaan fasilitas umum, tumpukan sampah yang perlu dibersihkan, jalan yang perlu diperbaiki, serta juga bisa mengetahui fasilitas mana yang harus diadakan atau di tingkatkan lagi. Sehingga penanganan pembenarannya akan lebih cepat. Informasi pembuatan E-KTP juga akan membantu masyarakat dalam mencari informasi pembuatan E-KTP mereka, sehingga mereka tidak bersusah payah mencari informasi tersebut di kantor kecamatan yang berwajib. Sistem dirancang meggunakan metode waterfall, pemodelan UML, pemodelan struktur data dan hubungan antar data ERD sedangkan bahasa pemrograman yang digunakan adalah PHP, dan untuk basis datanya menggungakan MySQL.
\end{abstract}

Kata Kunci: Fasilitas umum, E-KTP, pelaporan, sistem informasi, universitas mercu buana

\begin{abstract}
Public facilities provided by the government are a tool for the community to carry out daily activities. From the start of pedestrians, roads, traffic lights to landfills. In addition to public facilities, information on making E-KTP is also very helpful for the community in finding information on making E-KTP to make it easier. If there is damage or misuse of the facility, a corrective action or a quick solution is needed so that it can be reused. With the ignorance of the government or the surrounding apparatus regarding the damage or misuse it can cause disruption of the activities that occur every day. With the web-based application that I call "Report It" it can help the government or the surrounding apparatus to find out about damage or misuse of public facilities, rubbish piles that need cleaning, roads that need to be repaired, and also know which facilities should be held or increase again. So that the handling of justification will be faster. Information on making E-KTP will also help the community in finding information on making their E-KTP, so they do not bother to look for that information in the authorized sub-district office. The system is designed using the waterfall method, UML modeling, data structure modeling and the relationship between ERD data while the programming language used is PHP, and for the database it uses MySQL.
\end{abstract}

Keyword: Public facilities, E-KTP, reporting, information systems, Mercu Buana University

\section{PENDAHULUAN}

Fasilitas umum yang disediakan pemerintah bukan hanya berperan untuk menjadi sebuah pelengkap di jalan atau di sekitar daerah tempat tinggal. Namun fasilitas umum[3] bisa menjadi sebuah alat bantu dalam menjalankan aktifitas sehari-hari warga sekitar.
Selain fasilitas umum, informasi pembuatan E-KTP juga pastinya sangat membantu masyarakat dalam mencari informasi E-KTP mereka. Akan tetapi setiap fasilitas umum pasti ada masanya sendiri, atau disalah gunakan oleh pihak-pihak yang tidak bertanggung jawab, serta informasi pembuatan E-KTP masih belum ada di kecamatan cileungsi. 
Kerusakan[4] atau penyalah gunaan fasilitas umum yang terjadi harus mendapat penanganan secepatnya agar tidak timbul masalah dalam kegiatan yang berjalan. Seperti yang sering diberitakan di media mengenai kecelakaan[5] lalu lintas yang diakibatkan jalanan yang rusak, lampu lalu lintas yang tidak berfungsi, dan penyalah gunaan trotoar pejalan kaki yang tidak seharusnya, dan juga tumpukan sampah tidak berada di tempatnya yang tidak enak dipandang. Hal itu bisa akan terus terjadi jika fasilitas umum yang seperti itu lama mendapatkan tindakan atau bahkan terus dibiarkan dalam keadaan seperti itu. Sama seperti fasilitas umum jika informasi pembuatan E-KTP tidak dibuat, maka nantinya masyarakat terpaksa menanyakan secara manual ke kantor kecamatan yang berwajib sehingga tidak praktis.

Berdasarkan permasalahan yang ada, maka dapat disimpulkan bahwa untuk menjawab permasalahan tersebut perlu dibuat suatu aplikasi informasi berbasis web tentang pelaporan mengenai fasilitas umum[6] dan informasi pembuatan E-KTP yang dapat menyelesaikan masalah-masalah yang ada. Mengapa perlu berbasis web, karena masyarakat cenderung lebih memilih untuk membuka web pada menu browser yang dimiliki daripada harus melakukan pengunduhan aplikasi berbasis mobile untuk melaporkan sesuatu.

Berdasarkan latar belakang yang dijelaskan di atas, maka secara garis besar rumusan permasalahannya adalah:

1. Apa dampak dari ketidak berfungsiannya fasilitas yang ada?

2. Apa dampak dari ketidak tahuan masyarakat tentang informasi pembuatan E-KTP mereka?

3. Bagaimana cara pengelola mengetahui mengenai fasilitas yang tidak berfungsi atau rusak?
4. Bagaimana cara masyarakat mengetahui mengenai informasi pembuatan E-KTP mereka?

5. Bagaimana membuat aplikasi yang dapat menampung seluruh laporan dari pengguna mengenai fasilitas dan informasi pembuatan E-KTP yang ada?

6. Bagaimana aplikasi ini dapat membantu masyarakat dan pemerintah mengetahui dengan cepat mengenai kerusakan atau ketidak fungsian fasilitas dan informasi pembuatan E-KTP yang ada?

Apakah pemerintah dan masyarakat terbantu dengan adanya aplikasi ini?

\section{XAMPP}

XAMPP adalah perangkat lunak bebas, yang mendukung banyak sistem operasi, merupakan kompilasi dari beberapa program. Fungsinya adalah sebagai server yang berdiri sendiri (localhost), yang terdiri atas program Apache HTTP server, MySQL database, dan penerjemahan bahasa yang ditulis dengan bahasa PHP dan Perl. Nama XAMPP merupakan singkatan dari X (empat sistem operasi apapun), Apache, MySQL, PHP, dan Perl.

\section{Konsep Dasar Web}

Menurut Andi (2013 : 311) mengemukakan bahwa Web server adalah suatu program komputer yang mempunyai tanggung jawab atau tugas menerima permintaan PHP dari komputer klien, yang dikenal dengan nama web browser, [7] dan melayani mereka dengan menyediakan respon HTTP berupa konten data, biasanya berupa halaman web yang terdiri dari dokumen HTML, dan objek terkain seperti gambar danlain-lain

\section{Sublime Text}


Sublime Text adalah aplikasi editor untuk kode dan teks yang dapat berjalan diberbagai platform operating system dengan menggunakan teknologi Phyton API. Terciptanya aplikasi ini terinspirasi dari aplikasi Vim, Aplikasi ini sangatlah fleksibel dan powerfull. Fungsionalitas dari aplikasi ini dapat dikembangkan dengan menggunakan sublime-packages. Sublime Text bukanlah aplikasi open source dan juga aplikasi yang dapat digunakan dan didapatkan secara gratis, akan tetapi beberapa fitur pengembangan fungsionalitas (packages) dari aplikasi ini merupakan hasil dari temuan dan mendapat dukungan penuh dari komunitas serta memiliki linsensi aplikasi gratis.

\section{Basis Data}

Berikut ini adalah beberapa defini basis data menurut Fatansyah (2010:2) :

1. Kumpulan data yang saling berhubungan uang disimpan secara bersama dengan sedemikian rupa dan tanpa pengulangan yang tidak perlun untuk memenuhi berbagaikebutuhan.

\section{MySQL}

Menurut Mohamad Sukarno (20010:3) menyimpulkan bahwa "MySQL adalah merupakan perangkat lunak untuk DMS (Database Management System) karena sifatnya yang open source dan memiliki kemampuan menampung kapasitas yang sangat besar, maka MySQL menjadi yang sangat popular dikalangan programer web". MySQL dijalankan dala 2 sistem operasi yang sangat popular saat ini, yaitu : windows dan Linux[8]

\section{PHP MyAdmin}

PHP MyAdmin sebenarnya adalah sebuah aplikasi web yang ditulis menggunakan bahasa pemrograman PHP. Sebagaimana aplikasiaplikasi lain untuk lingkungan web (aplikasi yang dibuka menggunakan pramban atau browser php MyAdmin merupakan aplikasi web yang bersifat open source sejak pertama kali dibuat dan dikembangkan. Dengan dukungan dari banyak developer dan translator, aplikasi web phpMyAdmin mengalami perkembangan yang cukup pesat dengan ketersediaan banayak pilihan bahasa.

\section{METODE}

\section{Lokasi Penelitian}

Lokasi penelitian untuk memperoleh datadata yang diperlukan dalam membuat website ini adalah daerah Kecamatan Cileungsi, Kabupaten Bogor.

\section{Sarana Pendukung}

Sarana pendukung pada saat penulis melakukan penelitian yaitu lokasi untuk melakukan pertemuan dengan pihak terkait. Untuk pengembangan sistem aplikasi itu sendiri dibutuhkan perangkat:
1. Laptop
2. Internet

\section{Diagram Alir Penelitian}

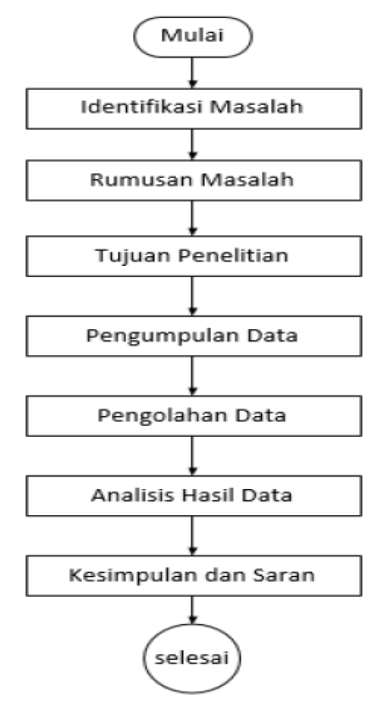

Gambar 1. Diagram alir penelitian

\section{Objek Penelitian}

Objek penelitian dilaksanakan wilayah Kecamatan Cileungsi, Kabupaten Bogor. Pada penelitian ini yang menjadi objek 
penelitian adalah kecenderungan masyarakat yang ingin melaporkan kerusakan fasilitas umum, sampah yang berserakan, memberikan saran kepada pihak terkait agar dapat meningkatkan atau mengadakan fasilitas tersebut, serta mencari informasi pembuatan EKTP mereka.

\section{Identifikasi Masalah}

Didalam melakukan penelitian, penulis menentukan rumusan masalah yang akan menjadi pokok permasalahan. Setelah melakukan survey di lapangan, maka masalah yang dihadapi oleh masyarakat dijadikan pokok permasalahan agar penelitian ini terarah tujuannya. Pokok permasalahan yang diteliti adalah masyarakat banyak yang ingin melaporkan kerusakan fasilitas umum, dikarenakan fasilitas yang rusak atau tidak berfungsi dapat menyebabkan terganggunya kegiatan sehari-hari, tetapi masyarakat tidak tahu bagaimana caranya melaporkan hal tersebut, serta mencari informasi pembuatan EKTP mereka tanpa bersusah payah pergi ke kantor kecamatan yang berwajib.

\section{Tujuan Penilitian}

Tujuan dari sebuah penelitian adalah mencari solusi dari masalah yang ada sehingga masyarakat dapat melaporkan fasilitas umum yang rusak, memberikan informasi pembuatan E-KTP, serta memberikan saran kepada pihak berwajib.

\section{Pengolahan Data}

Pengolahan data dilakukan berdasarkan data yang diperoleh dari kegiatan sebelumnya. Dengan melakukan observasi dan wawancara, penulis mendapatkan data-data apa saja yang menjadi masalah kebanyakan masyarakt dalam melakukan kegiatan sehari-hari, dan bagaimana cara mengatasi masalah tersebut tanpa membuat repot. Dengan melakukan observasi juga penulis bisa mendapatkan data pihak mana saja yang bertanggung jawab akan masalah tersebut.

\section{Analisis}

Analisis dilakukan terhadap hasil pengolahan data yang telah dilakukan sebelumnya. Analisis mengacu pada hasil yang diperoleh dari observasi dan wawancara yang dilakukan oleh penulis. Memberikan solusi dengan memberikan wadah untuk melapor pada pihak berwajib berdasarkan masalah dari kebanyakan masyarakat tentang fasilitas umum, dan informasi pembuatan E-KTP yang penulis dapatkan.

\section{Penutup}

Setelah dilakukan pengolahan data dan analisis terhadap hasil pengolahan data, ditarik kesimpulan dari penelitian yang telah dilakukan dan diberikan saran-saran untuk perbaikan dan pengembangan dimasa yang akan datang.

\section{HASIL}

\section{Analisis Sistem Berjalan}

Analisis sistem berjalan dilakukan untuk mengetahui bagaimana alur sistem, permasalahan-permasalahan yang ada di kantor kecamatan cileungsi dan juga memberikan solusi dari permasalahan yang ada.

\section{Analisis Proses Bisnis}

Kantor kecamatan cileungsi melakukan kegiatan pembuatan E-KTP, dan dilaksanakan setiap hari kecuali hari sabtu dan minggu. Masyarakat harus mengikuti proses pembuatan terlebih dahulu sebelum pihak kecamatan membuat E-KTP. Setelah mengikuti proses pembuatan, masyarakat akan diberi surat keterangan pembuatan EKTP yang harus disimpan sebagai alat bukti 
dan nanti ditukarkan ke kecamatan jika pembuatan E-KTP sudah selesai.

Selain melayani pembuatan E-KTP, kabupaten bogor juga mempunyai website yang melayani pelaporan masyarakat tentang masalah atau kerusakan[10] pada fasilitas umum. Tetapi, kantor kecamatan cileungsi tidak bertanggung jawab terhadap fasilitas umum seperti jalanan, trotoar penjalan kaki, rambu lalu lintas dan juga sampah. Melainkan dinas-dinas terkait yang bertanggung jawab akan hal-hal tersebut. Website pelaporan kabupaten bogor hanya menjadi wadah pelaporan masyarakat, yang nantinya laporan tersebut akan diteruskan kepada dinas-dinas berwajib.

\section{Analisis Kebutuhan Sistem}

Tahap analisis sistem merupakan salah satu usaha mengidentifikasi kebutuhan dan spesifikasi sistem yang akan diciptakan. Didalamnya akan dijabarkan apa saja entitas yang dilibatkan, proses yang dijalankan, serta output yang dihasilkan.

Berdasarkan analisis masalah yang dijabarkan diatas, maka sistem yang dibuat adalah sistem pelaporan fasilitas umum dengan spesifikasi sistem sebagai berikut :

1. Sistem yang akan digunakan yaitu berbasis web.

2. Sistem menyediakan layanan untuk pengguna yaitu dapat melaporkan kerusakan fasilitas dan juga memberikan saran kepada pihak terkait, selain itu juga dapat memberikan informasi E-KTP.

3. Sistem menyediakan layanan untuk admin yaitu melakukan pendataan, dan mengubah status laporan.

4. Sistem juga dapat memberikan informasi laporan apa saja yang sudah diverifikasi, ditolak, sedang dikerjakan, atau laporan yang belum dikerjakan.
5. Sistem juga dapat memberikan informasi kualitas kinerja pihak terkait dalam menindak lanjuti laporan dari pengguna.

\section{Use Case Diagram}

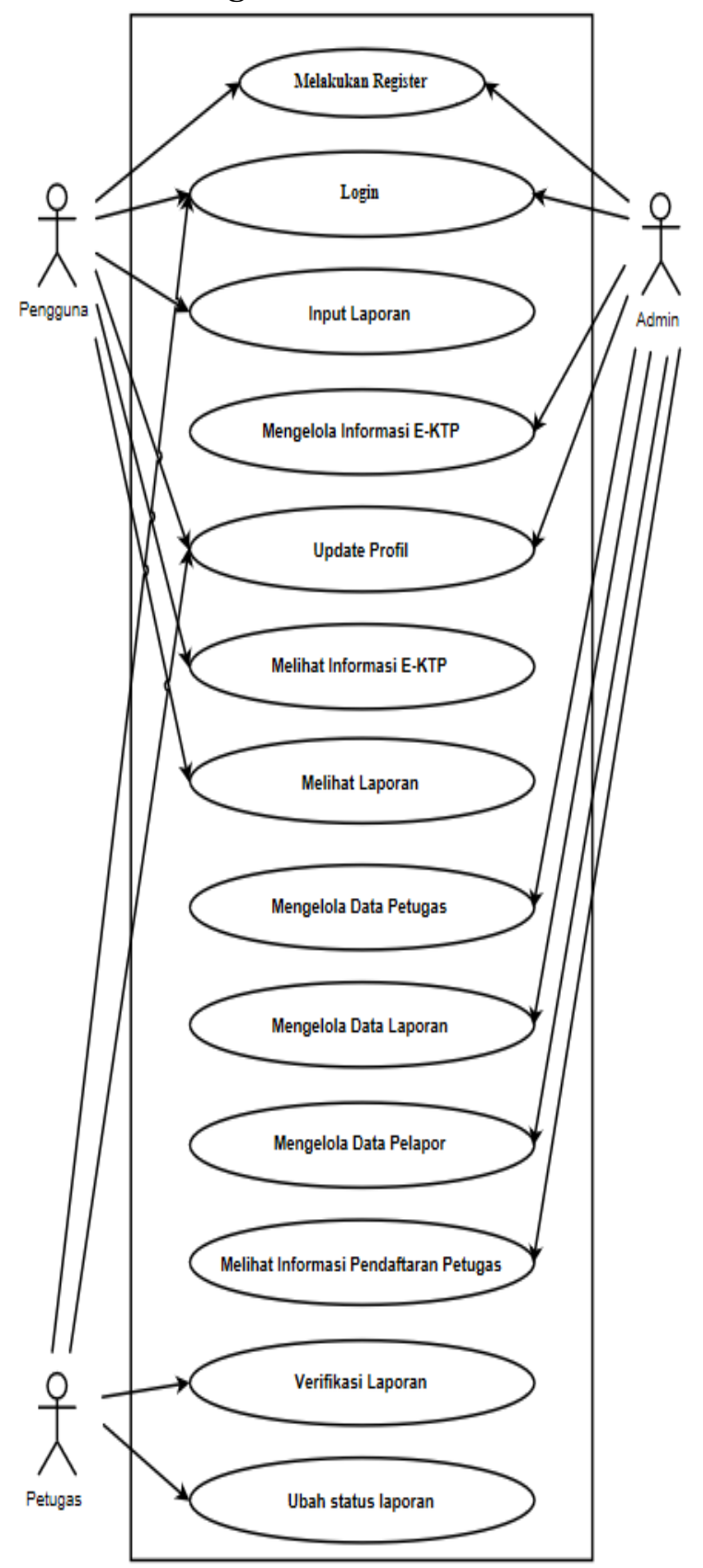

Gambar 2. Use Case Diagram

\section{Perancangan Antar Muka}


Volume 5 No. 1 | Januari 2020 : 1-8

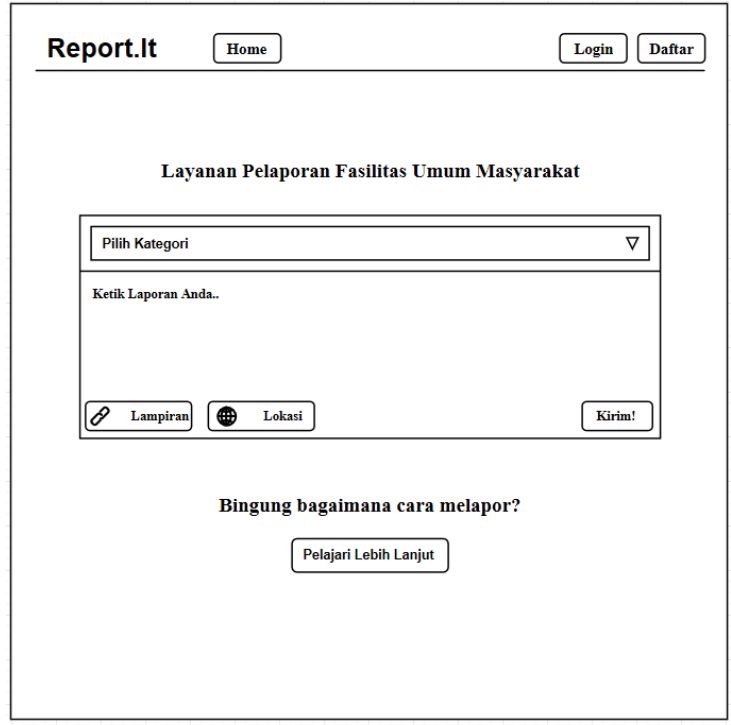

Gambar 3. Rancangan Antar Muka Home

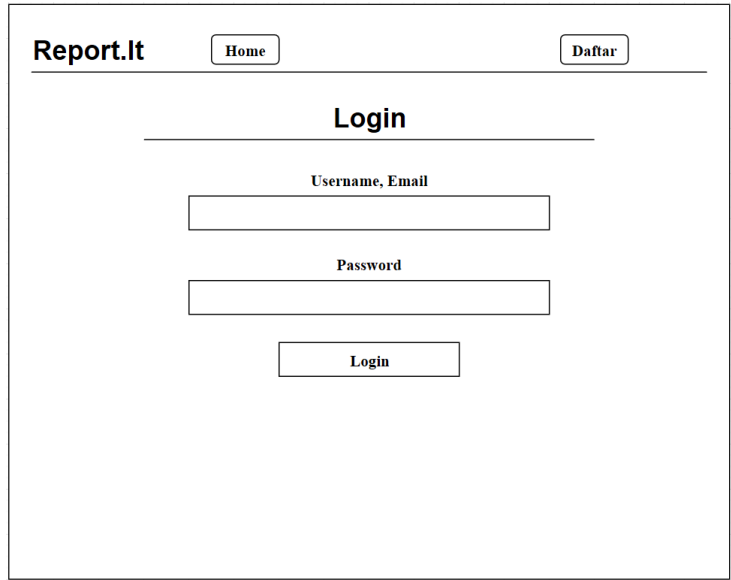

Gambar 4. Rancangan Antar Muka Login

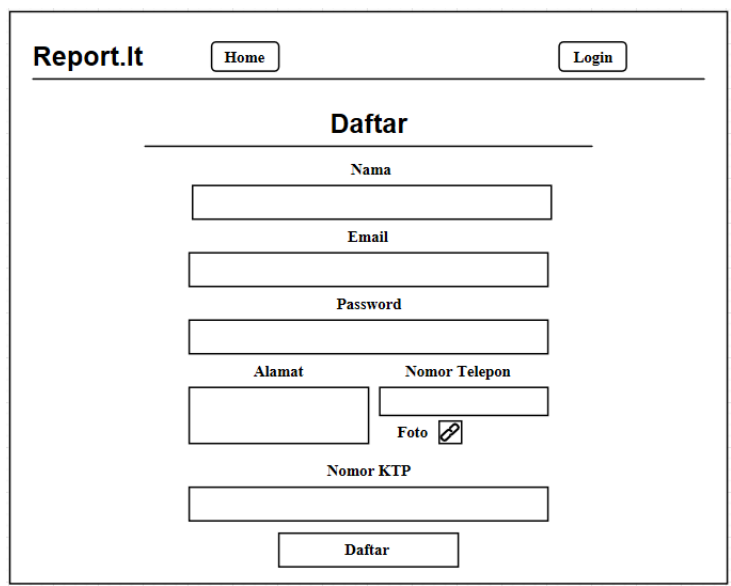

Gambar 5. Rancangan Antar Muka Pendaftaran

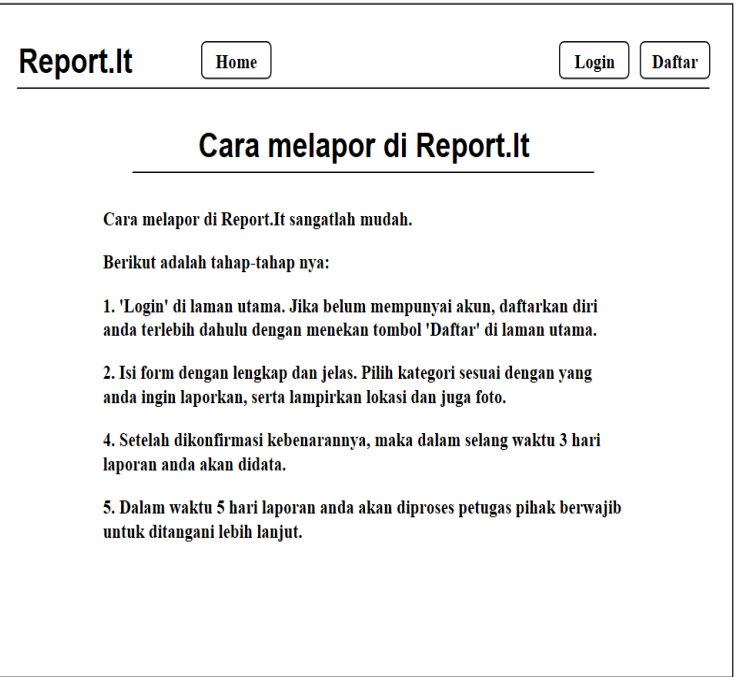

Gambar 6. Rancangan Antar Muka Tutorial

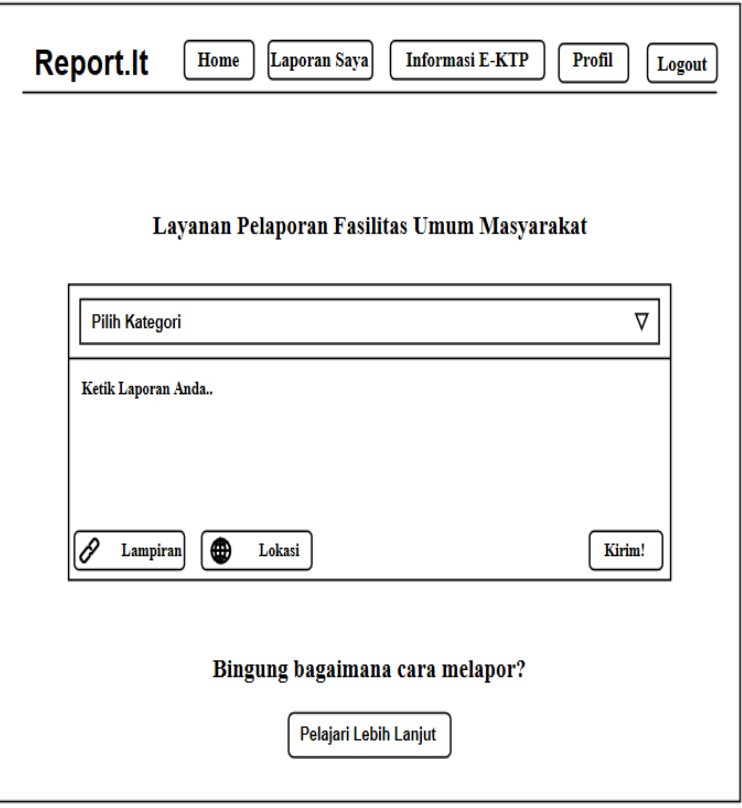

Gambar 7. Rancangan Antar Muka Pengguna

\section{Evaluasi Hasil Perancangan}

Berdasarkan kebutuhan dilapangan, evaluasi hasil perancangan Analisa dan Perancangan Sistem Informasi Pelaporan Fasilitas Umum dan Informasi Pembuatan E-KTP untuk Masyarakat, adalah sebagai berikut:

1. Website ini dibutuhkan oleh masyarakat yang ingin melaporkan fasilitas umum yang rusak atau 
disalah gunakan, sehingga aktivitas keseharian mereka tidak terganggu.

2. Website ini memberikan informasi pembuatan E-KTP yang dibutuhkan oleh masyarakat banyak, karena mereka tidak ingin repot-repot untuk pergi ke kantor kecamatan untuk menanyakan hal tersebut.

3. Webiste ini memberikan kemudahan kepada dinas terkait dalam mengatasi masalah fasilitas umum agar lebih aman dan juga rapi.

\section{KESIMPULAN}

Berdasarkan penjelasan yang telah diuraikan pada bab-bab sebelumnya tentang Analisa Perancangan Sistem Informasi Pelaporan Fasilitas Umum dan Informasi Pembuatan EKTP untuk Masyarakat (Studi kasus: Kecamatan Cileungsi, Kabupaten Bogor) maka dapat disimpulkan:

1. Penelitian ini menghasilkan rancangan website yang dapat digunakan untuk membantu masyarakat dalam melaporkan fasilitas umum yang bermasalah, dan dapat mengetahui informasi pembuatan E-KTP dengan lebih mudah. Dinas terkait juga terbantu karena dengan adanya sistem pelaporan ini dapat membantu mengetahui fasilitas umum yang bermasalah dan segera diperbaiki.

2. Dengan adanya website ini dinas terkait dapat lebih mudah mengetahui fasilitas umum yang bermasalah dan juga butuh perbaikan.

3. Website ini dapat membantu masyarakat dan juga dinas terkait dalam membangun daerah yang bersih dan rapi.

4. Memberikan kemudahan kepada kantor kecamatan dalam memberikan informasi pembuatan E-KTP kepada masyarakat.

\section{DAFTAR PUSTAKA}

[1] [1] N. E. Christian, Y. D. Y. Rindengan, P. D. K. Manembu, T. Informatika, U. Sam, and R. Manado, "Rancang Bangun Aplikasi Fasilitas Umum Berbasis Web Services," Ejournal Tek. Inform., vol. 8, no. 1, pp. 13-17, 2016.

[2] Rusdiyanto, "Sistem Informasi Goegrafis Pemetaan Fasilitas Umum Di Kecamatan Lubuklinggau Utara 1 Kota Lubuklinggau," Jutim, vol. 2, no. 2, pp. 99-105, 2017.

[3] M. Sholeh, "Sistem Informasi Geografis Fasilitas Umum Berbasis Web Kota Yogyakarta," Semin. Nas. Teknol. Inf. dan Komun., vol. 2013, no. Sentika, pp. 169-174, 2013.

[4] Muh Gian Nastiar, "Sistem pelaporan kerusakan jalan pada bina marga makassar berbasis web dan mobile," 2016.

[5] N. S. Samodra Teguh Bowo Kesowo, "Perancangan Aplikasi Pelaporan Kecelakaan Berbasis Web Menggunakan Framework Laravel dan Google Maps API pada Unit Kecelakaan Lalu Lintas Kota Salatiga," vol. 2, no. 672012182, pp. 1-10, 2017.

[6] M. Iqbal and G. Karya, "Sistem Informasi Geografis Fasilitas Umum Dan Sosial Di Kabupaten MapServer dan MySQL SPASIAL," vol. 1, pp. 203-218, 2012.

[7] M. Rinaldy, F. R. Deny, and A. R. Muhammad, "Aplikasi Pelaporan Kerusakan Jalan Tol Menggunakan Layanan Web Service Berbasis Android," Istek, vol. X, no. 1, pp. 117-123, 2017.

[8] W. H. I. Idria Maita, "Sistem Informasi Pelayanan Publik Berbasis Web Pada Dinas Pekerjaan Umum Kabupaten Kampar," vol. 3, no. 2, pp. 17-22, 2017. 
[9] A. Wicaksono, F. Pradana, and F. A. Bachtiar, "Pengembangan Sistem Pelaporan Kerusakan Jalan Berbasis Android Untuk Daerah Kota Malang Menggunakan Konsep Crowdsource," vol. 3, no. 4, pp. 3825-3831, 2019.

[10] S. P. Nina Setiyawati, "Perancangan Aplikasi Pelaporan Kerusakan Prasarana Berbasis Android Menggunakan GCM (Google Cloud Messaging)," no. November, 2016. 